Experiences of adjustment to secondary progressive multiple sclerosis: A meta-ethnographic systematic review

Christopher Meek $^{\mathrm{a}}$, Gogem Topcu ${ }^{\mathrm{a}}$, Nima Moghaddam ${ }^{\mathrm{b}}$ and Roshan das Nair ${ }^{\mathrm{a}, \mathrm{c} *}$

${ }^{a}$ School of Medicine, University of Nottingham, Nottingham, UK, ${ }^{b}$ School of Psychology, University of Lincoln, Lincoln, UK; ' Institute of Mental Health, Nottinghamshire Healthcare Trust, Nottingham, UK.

*Roshan das Nair, B19, Institute of Mental Health, Jubilee Campus, University of Nottingham, Nottingham, NG7 2TU, UK; Email: roshan.dasnair@nottingham.ac.uk 


\title{
Experiences of adjustment to secondary progressive multiple sclerosis: A meta-ethnographic systematic review
}

\author{
Abstract \\ Purpose: To provide an overview of the experiences and needs of patients \\ adjusting to life after receiving a diagnosis of secondary progressive multiple \\ sclerosis (SPMS). \\ Method: We conducted a meta-ethnographic synthesis of qualitative studies on \\ the experiences of transition to SPMS, based on a systematic literature search of \\ CINAHL, PsycINFO, Embase, MEDLINE, and Web of Science. Identified \\ studies were quality-appraised using a critical appraisal checklist, and individual \\ findings synthesised inductively. \\ Results: The synthesis included 12 articles with 144 people with SPMS. \\ Adjusting to SPMS transition encompassed a variety of reactions and coping \\ strategies. Successful adjustment was associated with accepting and adapting \\ coping strategies, and availability of social support and relationships. Clinical \\ services increased uncertainty around adjustment where patients felt clinicians \\ were not transparent with them about their changing diagnosis. \\ Conclusions: People adjust to SPMS in different ways, with the success of \\ adjustment influenced by a patient's primary coping mechanism. Coping \\ mechanisms are determined by pre-existing individual differences, alongside \\ engagement with, and quality of, social support networks and activities. Services \\ should ensure that people are provided with informational support about their \\ illness progression, and emotional support concerning coping strategies, social \\ networks, and physical activity, as these are key determinants of successful \\ adjustment.
}

Keywords: multiple sclerosis, secondary progressive, transition, adjustment, meta-synthesis, meta-ethnography

\section{Implications for Rehabilitation}

- Adjusting to secondary progressive multiple sclerosis is a difficult and stressful time for patients 
- Coping strategies patients use, their support network and their activity levels are key determinants of successful adjustment

- Clinicians should be open with patients about their assessment of their changing diagnosis, rather than trying to avoid upsetting the patient by withholding information

- Clinical services should be proactive in supporting patients during adjustment with learning positive coping strategies, and maintaining or increasing social relationships and activity levels

\section{Introduction}

\section{Rationale}

Multiple Sclerosis (MS) is a common neurological condition, affecting 2.5 million people worldwide, and 127,000 in the United Kingdom [1]. For the majority, MS presents initially as a series of relapses, each followed by a period of recovery. When there is a lack of disease progression between these relapses, this is referred to as Relapsing-Remitting MS (RRMS). Secondary Progressive MS (SPMS) is defined by progressive accumulation of disability after an initial RRMS course, which may or may not contain sharp episodes of decline during progression [2]. This progression from RRMS to SPMS happens within 15 years of initial diagnosis in 50\% of cases and takes a median of 20 years $[3,4]$.

It is challenging for clinicians to objectively identify the transition from RRMS to SPMS, due to subtle changes in symptoms. Consequently, receiving a new diagnosis of SPMS can take an average of almost three years after onset of progressive symptoms [5]. From a psychosocial perspective, the transition from RRMS to SPMS can be a very psychologically demanding time for people with MS (pwMS) and their carers, fraught 
with uncertainty and stress, and associated with negative psychological effects $[6,7,8]$. Clinicians describe the impact for pwMS of receiving an SPMS diagnosis as similar to that of receiving the initial MS diagnosis - "like being diagnosed again" [9,p.460].

Alongside the need to adapt to a disease course with a more progressive deterioration and unremitting symptoms, adjustment to SPMS presents additional challenges, relative to those of adjusting to the initial diagnosis. A patient with RRMS has disease modifying therapies and treatments available [10], but these are frequently withdrawn after progression to SPMS. This treatment-withdrawal is accompanied by less frequent contact with specialist MS services and neurologists, precisely when the patient's physical condition is becoming more debilitating and posing ever-greater activity limitations [11]. Unsurprisingly, this is often a period of stress, worry, and fear of what the future holds, and has been argued to be a "fear point" of the condition $[12, p .8]$ where appropriate intervention and communication is crucial to help people adjust and cope with the transition, or risk it being "devastating and demoralising" $[13, \mathrm{p} .18]$.

Compared to other aspects of the condition, little research had been conducted into progressive MS [14]. Recently however, researchers and stakeholders have recognised this lacuna, and we now have some understanding of the needs of people with MS across the lifespan [15], with some research examining SPMS specifically [16]. In terms of adjustment, studies have explored how pwMS adjust to "advanced" (more physically restricted) stages of the disease, but such studies [e.g., 17, 18, 19] either do not specify the MS subtype or fail to address adjustment to SPMS directly.

A large-scale UK study showed that those with SPMS have higher rates of distress (anxiety, depression) than other MS subtypes [20], and significantly reduced quality of life $[21,22]$. This increased distress may reflect poor adjustment to the 
secondary-progressive stage - and a lack of understanding by healthcare professionals about how to meet the needs of this population when compared with the less-distressed RRMS population, whose needs are better understood by clinicians. Increasing understanding of the needs of people adjusting to SPMS is therefore crucial so services can provide appropriate clinical and cost-effective support. A large-scale international study found the cost burden of patients in later stages of MS can be three to fourfold more compared to earlier stages [22]. This may be in part due to a lack of research into appropriate care provision, in addition to the increase in support needs.

Recognising the need to improve understanding of adjustment to SPMS - in order to better support people through this process - investigators have started to gather qualitative data on SPMS-adjustment experiences. These data can support theory development - identifying core needs during adjustment and factors that seem to influence this process - which can in turn inform intervention development and selection. Indeed, the authors of one grounded theory study have outlined a preliminary conceptual model of changes in adjustment over time with progressive MS [12, 23]. Bogosian et al. [24] found that people with progressive MS adopted three different "adjustment modes", or ways of coping following the initial adjustment. These were "Scaling back", "Resigning" and "Finding alternatives" (p. 349), which people constantly navigated and fluctuated between to manage the demands of their condition. We aim to advance this work (which was based on a single study) by synthesising across all available qualitative studies of the adjustment experience in SPMS. Our approach to synthesis will be informed by this preliminary model, but also apply an inductive process - open to data-driven insights from a broader reading of the available literature. 


\section{Objectives}

In order to improve our understanding of adjustment experiences in people with SPMS - and how best to support people during this process - there is a need to synthesise the growing (but disparate) literature that captures these experiences. Given the small sample sizes of many of the extant qualitative studies, a qualitative synthesis can bring together a broad range of participants and descriptions to develop overarching interpretations that emerge from synthesising findings from primary studies [26]. This then has the potential to provide a larger, yet focussed, overview of the research. This meta-synthesis, therefore, aimed to systematically synthesise the findings of previous qualitative studies regarding the experiences and needs of patients adjusting to life at the time of, and following, receipt of a diagnosis of SPMS.

\section{Materials and Methods}

\section{Overview}

This meta-synthesis was prospectively registered with PROSPERO International Register of Systematic Reviews (Registration number: CRD42018103782, 19.07.2018). Meta-synthesis brings together qualitative research in order to generate new theoretical or conceptual ideas, identify gaps in the literature, inform the development of other studies, and present evidence for development, intervention, and implementation of health-based interventions [27]. This study had three stages: (1) systematic search, (2) critical appraisal, and (3) synthesis, using a critical realist approach to metaethnography to identify core meanings in the text [28, 29]. 


\section{Systematic Search}

\section{Search Strategy}

The search strategy was developed using the CHIP (Context, How, Issues of Interest and Population) tool [30], which can be seen in table 1. This tool helps formulate the search strategy by breaking down the research aim into its component parts.

\section{[INSERT TABLE 1 HERE]}

The final search strategy was adapted to the syntax and subject headings of each electronic database used (see below). The final search terms were combined using the Boolean logic terms (“and" and "or"). Relevant database index terms (subject headings) were exploded where possible (to capture all specific/narrower terms relating to the broader index term). Once a list of suitable studies had been identified through the database search, reference lists were checked to maximise identification of potentially relevant studies to be included in the meta-synthesis.

The following electronic databases were searched due to their relevance to the topic area: MEDLINE, Embase, PsycINFO, Web of Science, and CINAHL. The search was from 1980-October 2019, as scoping exercises with earlier dates produced no further papers. An example of the search strategy for Embase can be found in appendix 1.

\section{Inclusion criteria}

Studies were considered for inclusion if they included adults with SPMS, used a qualitative research method (with participant quotations), focused on adjustment, published in a peer-reviewed journal, and published in the English language. Mixed 
samples of participants (e.g., with other MS subtypes) were included if specific data could be discernibly attributed to an SPMS participant.

Initially, duplicates were removed after exporting records to EndNote. Title-andabstract screening was then conducted against the inclusion criteria by the lead author (CM). Full texts were retrieved and reviewed for all articles that could not be excluded based on title/abstract alone.

\section{Critical Appraisal}

The quality of included studies was assessed using the Critical Appraisal Skills Programme (CASP) [32] qualitative research tool. We selected the CASP because it assesses all of the features that have been identified as core markers of quality in qualitative research [33] whilst accommodating diverse qualitative study designs and theoretical positions. We did not seek to exclude papers from the analysis based on quality, due to the previous tension between reporting quality and relevance, as it has been argued that excluding a paper based on its reporting quality may not be reflective of its value in a synthesis [34]. Initially, all articles were appraised by CM to assess their quality and eligibility for inclusion against the CASP. Following this, a random sample of the included articles were assessed independently by at least two reviewers (CM, NGM and GT), with disagreements arbitrated by RdN.

This review evaluated each paper using the Dixon-Woods et al. [34] and Malpass et al. [28] method for differentiating between "key papers" (which are conceptually rich and could make an important contribution to the synthesis) and "satisfactory papers" (which may or may not contribute significantly to the synthesis) to reflect relevance to the topic. Differentiation between "key" and "satisfactory" papers was conducted to "test" the contributions of the papers at a later stage, examining whether the synthesis remained the same if only key papers were included. 


\section{Synthesis}

Meta-ethnography $[28,29,35]$ was used for synthesising the qualitative data. This involved the "translation" of qualitative studies into one another [29] to develop new conceptual insights by comparing and contrasting article themes (i.e., second-order themes), to develop third-order themes. Rather than building themes from the raw qualitative data (i.e., first-order constructs), the focus of meta-ethnography is to create third-order constructs (i.e., our interpretations) from second-order constructs (i.e., original authors' interpretations of participant data).

\section{Extraction and Translation}

In the first stage, all papers were read several times by $\mathrm{CM}$, and the themes relevant to SPMS adjustment extracted. After extraction of the themes, "translation" occurred, whereby each article's themes were merged into a coherent set of overarching themes. This began by linking common themes together, preserving original terminology used in the papers where possible, starting with the themes from paper 1 , then adding themes from paper 2 and so on. Once themes from all articles (i.e., secondorder constructs), had been extracted, CM then conducted a process of interpretation, "translation", where third-order constructs were created by linking the second-order constructs together.

\section{Synthesising translations}

The final stage was synthesising the translations iteratively. This was determined by how the studies were linked to one another. There are three possible forms of synthesis: reciprocal, where concepts of one study could easily encompass another; refutational, where concepts are contested across papers; and line of argument, where studies are arranged in an order to achieve a fuller account of phenomena which 
"allows us to construct an argument about what the set of ethnographies say" [36,p.1349]. In this synthesis, a line of argument approach was used [36], as concepts between papers were variably expressed yet broadly reciprocal, and were thus suited to incorporation within a broader line-of-argument - supporting an integrative understanding of adjustment that goes beyond component concepts.

\section{Results}

\section{[INSERT FIGURE 1]}

Of the 2,403 study records identified for inclusion in this review (See figure 1 for PRISMA diagram), 12 papers met the inclusion criteria (See table 2 for study characteristics and for the assigned reference numbers for each paper), all published between 2008-2019. Eight of the 12 studies were based in the UK $(1,2,4,5,6,7,9$, $11)$, two in Italy $(3,8)$, and two in Sweden $(10,12)$. One of the 12 studies used focus groups (5), with 11 using semi-structured interviews either face-to-face, or over the phone. The age range of participants was 19-77 years. Four studies had only participants with an SPMS subtype $(2,4,11,12)$, with the remaining eight studies having participants with a mixture of MS subtypes, but with specific data available from those with SPMS on adjustment. One study (12) only had women participants, with the other studies having participants of different genders. Women were more strongly represented across all studies, which is consistent with the wider demographics of pwMS [37].

\section{[INSERT TABLE 2]}

The outcome of the quality appraisal assessment can be viewed in table 3. All papers were assessed using the CASP checklist as "valuable" to the synthesis. Four studies $(1,2,4,11)$ were considered highly relevant "key papers", with the remaining eight studies considered "satisfactory papers" [28]. 
[INSERT TABLE 3]

\section{Translation of second order constructs}

Translation of studies followed the process detailed by Malpass and colleagues [28]. The outcome of this translation process can be seen in table 4 .

\section{[INSERT TABLE 4]}

\section{Synthesising Translations}

When exploring the experiences and needs of people adjusting to SPMS, five themes and 12 subthemes were identified from the data.

\section{Theme 1: Coping Strategies}

A variety of coping strategies in managing adjustment to SPMS were identified. These are discussed below.

Subtheme 1: Denying and Concealing

Many participants used "denying" (i.e., refusing to personally accept the progression of the illness) and "concealing" (i.e., hiding illness progression from others) as coping strategies.

Struggling to accept the irreversibility of the condition through attributing their changing disease pattern to causes other than SPMS was one reason for participants using denial as a coping mechanism: "I thought it was a relapse, that it would get better ... I couldn't face the fact ... that that's [SPMS] it" (11, p. 1824). This coping mechanism was time limited among participants, who eventually could no longer deny the condition to themselves: 
It's almost like a different world. You know, which, you kind of know that you'll probably have to join sometime, but you're just kind of thinking well not yet please. $(6$, p. 483$)$

Another reason for use of denial as a coping mechanism appeared to be exacerbated by the perceived uncertainty of healthcare professionals in confirming the transition:

I cannot accept something that is threatening me ... They [healthcare personnel] could not confirm. ... They didn’t know. (12, p. 422)

Perceptions of the future varied across studies, with some evidence of coping through a denial of inevitable disease progression $(4,7)$ - which included participants being hopeful for a cure or expecting an improvement in or maintenance of current disability. One participant was unable to detail strategies for self-management when asked by researchers, instead spending his time seeking a cure:

There might be a cure! ... I spent quite a while on the internet ... This Italian guy has found what he thinks is a cure ... I thought well no-one's going to make that kind of statement unless they know something. (7, p. 327)

Concealing disease progression was another method of reported coping. This included privately acknowledging their worsening symptoms whilst behaving in ways which contradict and conceal it. One paper (11) described a participant determined not to change his lifestyle, struggling to walk across his driveway to enter a taxi to work each morning. The following quote describes another participant looking back on a time 
when they strove to conceal their SPMS from others, working hard to disguise its impact:

I kept it [SPMS] hidden because, which in hindsight was, well I don’t know...

This kind of constant managing and juggling and trying to keep it hidden. (1, p. 350)

Like "denying", people were able to use "concealing" initially, but eventually due to disease progression, were forced to change their coping style: "I got to a stage where I could no longer, oh I don't know, lie to people that I wasn't in pain.” (1, p. 349)

Subtheme 2: Reducing and Resigning

Another way of coping identified in past research is through "reducing" previously rewarding activities that are no longer enjoyable. This method of coping was negatively reinforced through the avoidance of distress, and generally led to a lessening in quality of life $(1,4)$. One participant described the negative experience of having a fall, and how this led to a reduction in leaving the house and confidence:

I had a bad fall last week where I split all my head open, so I am feeling a bit lack of confidence in just going out for a little walk up the road and back with my walker on my own. $(2$, p. 7$)$

Disease progression did not only bring a lessening of activity away from the home, but also in household routines. The following participant would rather avoid their routine altogether than make environmental adaptations to make it possible:

I miss being able to go out and hang washing out, but it's not worth it, it's not worth the hassle of everything I think would have to be in place ... hand rails, oh no no. $(1$, p. 350$)$ 
A reduction in previously enjoyed activities with friends and family members was a common experience reported among participants in one study (1):

I have got a wonderful family, children, and grandchildren ... but things are very dull because there is no way you can do things that you used to do. (1, p. 351)

Coping through "resigning" oneself to the hopelessness of life with the condition was another common strategy, especially among those living alone (1): "you just have to say goodbye to your previous life ... [spontaneity] isn't possible anymore" $(11, \mathrm{p}$. 1825). Participants commonly reported on specific lost activities and generalised this to an overall sense of inefficacy "it's robbed me of a lot of my life ... I just feel the world has shrunk" (1, p. 353). Using this coping mechanism, like "reducing" above, led to a decrease in quality of life $(1,4,7,11)$. This participant felt guilty for coping in this way:

I know I should be saying what I can do, that's the positive side of things ...

Because that's the way I always were before and I'm not like that now, so. It's like it's gone. (7, p. 329)

\section{Subtheme 3: Accepting and Adapting}

Learning to accept life as it had changed, "accepting", was a commonly reported, but often difficult to implement, coping style - with some participants feeling like they had "no damn choice" (11, p. 1825). Several studies highlight the importance of planning for the present, rather than looking towards the future (11):

I believe that the key to accepting your illness is what is really important ... But you have to think. ... instead of thinking that your life is over ... What do I like to do? How can I do it now? (12, p. 423) 
Across all key studies $(1,2,4,11)$, being active and having social contacts were strongly associated with this coping style:

My husband put me in the car, and we went to [city] where there is a big shopping unit ... we had a marvellous time. So there you are, that's what my husband did. (1, p. 352)

Twice a week I go to yoga with a lot of people who also have MS ... they're very supportive and that sort of makes life a bit easier. $(4$, p. 5$)$

The most frequently reported coping style was coping through "adapting" and finding alternative ways to make life fulfilling. Like "accepting", the ability to adapt was related to the presence of social support through family, friends, or charities, although social support networks were commonly reported to diminish in this patient group (7).

I still do things, you know ... I do phone calls for my husband's company ... I do things with my mum, other family, you know, my cousins. But I just have to learn to pace it and if I'm having the bad day then I know I can't get loads done. $(1$, p. 350$)$

Everything's had to be tailored down ... you just adapt, it's a struggle and there's no two ways about it ... you get used to that $(2$, p. 9)

Making the most of their current level of functioning through keeping active was reported across all key papers $(1,2,3,4,11,12)$, and helped the following participant cultivate an attitude of positivity which helped with their adjustment: 
I've still got to make the most of the time I've got while I can walk around and do things ... So I suppose I'm still using the same strategy as I used when I was first diagnosed. Do as much as you can while you can. (11, p. 1826)

Overall, participants who adopted more "accepting" or "adapting" coping styles and carried on being active despite it being a struggle at times, generally presented as having a richer quality of activities and were better emotionally adjusted.

Going out with friends, going out for dinner ... which I would have quite enjoyed before and not thought anything about it, but now I think "oh do I really want to go?", but then I force myself, you have got to go, because when I do go, I do enjoy it and I do feel better, your mood is lifted. (2, p. 9)

\section{Theme 2: Symptoms}

This theme concerned the impact of the symptoms of SPMS.

Subtheme 1: Physical

Physical symptoms of SPMS were reported across papers, particularly in the context of behavioural restrictors or causing emotional distress. Physical symptoms were reported far more frequently than cognitive symptoms, and fatigue $(4,5)$ was one of the symptoms most commonly reported as disabling.

Somebody at an earlier stage [of MS] might be concentrating on how to get through a working day, somebody at a later stage on how can I not spent 20 hours in bed? $(5$, p. 460$)$

Some days tiredness overwhelms me. (4, p. 5) 
In the quote below, a participant explains that they are now housebound due to the pain associated with the SPMS leading them to reduce activity:

I don't go out anymore I'd rather stay in ... I'm hurting more and I've got constant pain in my eyes and I find I can't handle it and by 9 o'clock I'm in bed. $(4$, p. 5$)$

Subtheme 2: Cognitive

Cognitive symptoms were reported, however struggles with concentration were framed as restricting behaviour and contributing to stress/distress:

My concentration goes very quickly and I get quite short-tempered very quickly. $(1$, p. 353)

A worsening of physical and cognitive symptoms was unavoidable for patients and forced them to abandon "concealing" and "denying" coping styles $(1,4,11)$.

\section{Theme 3: Importance of relationships}

A key theme across papers was the considerable impact of relationships in adjusting to SPMS.

Subtheme 1: Social Connectedness

Some studies reported the loneliness participants felt due to reduced support from professionals alongside a shrinking social support network. When support is "absent or dysfunctional" (3, p. 7), this can have a significant impact on loneliness and quality of life: 
I only want friendship, a chat. They [care workers] don't have to stay for hours... 10 minutes would be enough... I just want someone to make me talk, make me laugh! (3, p. 7)

Do you know it would be nice just to have somebody there saying you're doing a grand job, because you're socially isolated. $(2$, p. 9)

However, sometimes people felt uncomfortable discussing problems with others, such as their carers, as they thought they would "sit there and worry" $(4, \mathrm{p} .6)$. Professional support of some kind was particularly important for those who lived alone: You feel so bereft, you know, as though you're there, you are unwell and there's no one, you know, there's just no one. And particularly, being on my own. (1, p. 354)

All key studies mentioned the importance of good supportive relationships with family, friends, and support organisations to promote adjustment. Better practical and emotional support was found to be helpful in encouraging more "adapting" or “accepting" coping styles during transition $(1,4,11)$.

Several studies reported on the benefits of people engaging with charities and support groups where they can meet others with the condition. Participants with stronger social and professional support networks were more likely to foster adapting and accepting type coping styles and were less emotionally distressed. This finding was consistent across all key papers $(1,2,4,11)$.

You cannot describe it [meeting others with MS].... It's like heaven in some way to meet others with the same [experience of illness]. (12, p. 423) 
One study participant offered a contrasting opinion to the dominant narrative, highlighting how this is not the case for everyone, and that some may find the presence of others with SPMS aversive. In this study, this participant viewed MS support networks like a "cripple club" (6, p. 483) and so would avoid these events. Here, a desire to deny their own condition is threatened when they are faced with meeting other pwMS with greater physical deterioration (6):

But get in with a whole load of 'em [pwMS]. I couldn't. No, I couldn't go to [local club], thank you very much. $(6, \mathrm{p} 483)$

Many papers highlighted that people's experiences of receiving a diagnosis of SPMS was different to their initial diagnosis in terms of the support provided by health services. Several authors highlighted that follow-up support was described as lacking compared to that provided upon initial MS diagnosis, with patients being "left to get on with it" (4, p. 5), which led to feelings of abandonment (11).

When you're newly diagnosed there are people who'll help you...Y You go on to secondary progressive and there's nothing to tell you what's happening and what's what. $(5$, p. 460)

Participants reported that support from services is no longer proactive, and instead there is a requirement for them to continually ask for information, or support "I feel like I am being left to my own devices" (2, p. 8). This can make patients feel guilty, and as though they are pestering staff (11):

I think that when you are first diagnosed you get a lot of help, afterwards you just get left alone, nobody does anything and you have to keep going on and on saying I want this, I want this. (4, p. 5) 
The type of support needs expressed by participants varied across studies. In one key paper (1), psychological therapy helped a participant who was initially using a "resigning" coping style learn different coping strategies. Other key papers discussed the need for follow-up support from professionals and others with MS, both immediately after SPMS diagnosis and in the years beyond $(4,11)$. What was apparent across papers was that if emotional needs were not met, and participants did not have someone understanding to discuss their condition and feelings with, then this led to higher emotional distress $(1,2,3,4,11)$. One participant expressed frustration at being unable to speak about the condition with a partner: "I am not able to speak with him about the disease ... [other people] do not understand!"’. (8, p. 901)

\section{Subtheme 2: Sexuality}

A less frequently mentioned subtheme of relationships was the impact of SPMS on sexuality (3). One participant mentioned that sexuality had been affected because of her symptoms worsening, but she was able to adapt and find other ways to make life meaningful: "a sex life is one of the many things you miss ... but I adapted, concentrating on other things, that way I overcame it." (3, p. 8). From the same study, another participant initially gave up on ever having another sexual relationship after receiving SPMS. However, after adapting and meeting someone new, her sexual expectations changed:

I cancelled men... denied everything... become completely asexual. Then thanks to a person I recovered some desire... and the desire has become quite strong... in short, now I've re-found myself. $(3$, p. 8$)$ 
A common thread between papers was a strong feeling of loss among participants.

Subtheme 1: Independence

A perceived loss of independence was a common theme reported across papers $(1,3,4,7,10)$, which often accompanied a reduction in physical activity:

It's better I don't say how long it's been since I've been out... months. It's really really difficult. $(3$, p. 4$)$

This led to a sense of anger or frustration at being unable to perform tasks that they could once perform and becoming dependent on others:

I absolutely despise dependency, I hate it ... I have always been very independent. (1, p. 353)

A sense of dependence was evident across coping styles but was particularly prominent in those who struggled to accept their condition and felt like they should be able to do more $(1,3,4)$. It was also apparent in those with more "resigning" coping styles (10). One participant felt a sense of loss after allowing themselves to depend on others to complete effortful household chores, which they themselves had resigned to completing, but still they still identified as their responsibility:

This place [participant's house] is not well cleaned at all ... for some reason I have changed ... I can't explain it but they [the cleaning and putting things away] are my tasks. $(10$, p. 777$)$

Subtheme 2: Role 
A perceived change in identity, specifically in terms of loss of previous valued roles, was identified across many studies. This included loss of previous status as a selfsufficient worker, being unable to engage in official employment $(4,5,8)$ or domestic chores (10) as they did previously. A restriction in engagement in occupations led one study participant adopting a "resigning" coping style to conclude: "I live, but have no life." $(10$, p. 778$)$

\section{Subtheme 3: Confidence}

Participants expressed concerns about how they were seen in the eyes of others, stemming from a sense of embarrassment, fear, and lack of confidence (1): "you get insecure in yourself many times" $(12$, p. 421). The physical effects of the condition on balance and coordination led them to believe others perceived them as "drunk" (7, p. 325), comical, or different to before:

They [other people] are relating to me differently because they see the person who is wobbling around and can't get out of the chair. (1, p. 351)

\section{Theme 5: The time of the SPMS diagnosis}

\section{Subtheme 1: Delivering the SPMS Diagnosis}

The SPMS diagnosis was repeatedly reported as being delivered in an unplanned or insensitive way. Some participants learned about their SPMS diagnosis without being told directly, and this included overhearing the GP speaking about them on the telephone (4), or by inadvertently viewing a medical note with a queried diagnosis on it (7). Other papers highlighted clinicians' lack of sensitivity and empathy when delivering the SPMS diagnosis, and the need for additional training for healthcare staff to help support patients with processing the news (11). 
Several papers also reported on the amount of time patients had to wait to receive a diagnosis, and the reluctance of healthcare professionals to provide a diagnosis of SPMS. Patients often reported that they felt they were being "fobbed off" (7, p. 323) by healthcare professionals and the diagnosis was withheld from them:

They [healthcare professionals] had all different kinds of ways of saying that we don't know. (12, p. 422)

This delay in delivering the SPMS diagnosis may have been due to the subtleties of changing symptoms and uncertainty of diagnosing the condition, and participants reported they felt that healthcare professionals were unable to fully understand when the transition occurred or how their diagnosis was reached:

What do you determine or what do you look at in a person to then decide what MS they now have? (4, p. 5)

Several authors argued that delivery of the SPMS diagnosis and appropriate information needs to be provided sensitively in a hopeful and empathetic way, allowing patients enough time to process the news and answer any questions they may have in a two-way process with healthcare professionals $(4,11)$. Healthcare professionals "sugar coating” $(4$, p. 8$)$ or choosing to withhold information can lead to patients feeling betrayed and patronised, with too much information generally being seen as better than not enough information. Clinicians appeared reluctant to inform patients because they felt it risked upsetting them, however, the evidence points to the uncertainty around diagnosis causing more distress than the information, and that information should be shared collaboratively. Across papers, we observed that fulfilling patients' 
informational needs reduced their uncertainty and helped them to more readily come to terms with (i.e., be "accepting" of) their condition.

Subtheme 2: Reaction to the SPMS diagnosis

The initial reaction to receiving the SPMS diagnosis ranged from shock to ambivalence based on the participant's pre-existing understanding of the condition in relation to their own symptoms, which is explored in depth in themes across three key papers $(2,4,11)$. For many, receiving the SPMS diagnosis was expected and something they had already mentally prepared themselves for:

The neurologist said to me, 'You do realise you're secondary progressive?' and I said 'Yeah I've worked that one out.' (4, p. 5)

Others found it was not only expected, but also provided additional clarification about changes they had already noticed in their disease pattern:

It just made sense to me, in what was happening to me ... it just described the condition more. (11, p. 1825)

In some papers, participants received the SPMS diagnosis with ambivalence, viewing it as "just a label" (4, p. 4). The subtype of MS was not regarded as important by these participants, due to the disease being progressive anyway:

Primary, Relapsing Remitting, Secondary it's all progressively deteriorating. $(11$, p. 1826)

Although participants sometimes expected the SPMS diagnosis, it was also described as a psychological blow (11), and participants had a "cynical" (2, p. 8) view of the availability and usefulness of future treatments for SPMS on the UK's National 
Health Service. It was accompanied by the realisation that they would not be offered more treatment, or additional appointments with a neurologist, which was interpreted as care being “down-graded" (4, p. 6) and medical professionals being disinterested in them (2). A strong emotional reaction to the SPMS diagnosis was accompanied with concerns that this meant an imminent deterioration of the condition, and the realisation that things would no longer improve, which triggered feelings of loss around former status and future plans (4). Participants used "resigning" and "denying" styles of coping with receipt of the SPMS diagnosis:

So there's a bit of a 'so what' about it... I don't welcome this [SPMS diagnosis] news... life is going to be horrible. $(11$, p. 1825)

I was shocked that I got signed off work ... I just thought, you know, if I sleep then I'll be alright. (2, p. 8)

There was a real sense throughout the studies of the amount of emotional distress participants felt during transition, which included: anxiety and dread, anger ("It's just going to stick around, the $* * * * * * *$ !" $(11$, p. 1825)), sadness ("you're grieving" (4, p. 5)), and guilt ("sometimes it feels as if one is in the way" (10, p. 777)). Those who felt the most emotional distress often expressed greater concern about their physical symptoms, used "resigning” or "reducing” coping strategies, perceived themselves as incapable, and perceived others as judging.

\section{Line of Argument}

The most prevalent and salient findings from the themes above are now brought together to construct a "line of argument". Figure 2 represents a synthesis of the main findings. It demonstrates the effect that supportive relationships, independence, and 
professional emotional and informational support during and after SPMS diagnosis have on the coping strategies that persons with SPMS employ and their subsequent quality of life.

\section{[INSERT FIGURE 2]}

Soon after the receipt of a diagnosis of SPMS, in the early stages, people can cope through "concealing" and "denying" that the transition is occurring. However, eventually, their progressive physical deterioration forces them to adopt another coping strategy. The strategy adopted is influenced by the psychosocial influences on adjustment (along with individual differences [38] and pre-existing coping strategies).

Those with primary coping mechanisms of "accepting" or "adapting" increase the likelihood of successful adjustment to SPMS, and conversely those with a coping mechanism of "reducing" or "resigning" decrease the likelihood of successful adjustment. A unified theory of adjustment to chronic illness defined "successful adjustment" as the ability to return to "equilibrium" (i.e., less distress, less impact on roles and relationships, good illness management and high positive affect) [25]. Return to equilibrium is represented in the line of argument as "Accepting Life \& Adapting Activity".

The primary influences that contributed to persons with SPMS using an “Accepting Life \& Adapting Activity" coping strategy are: having a strong social support network ("Family and Friends"), having healthcare professionals meet their informational and emotional needs ("Professional Support"), and retaining control over life and behaviour ("Independence"). Conversely, a lack of these factors (i.e., "Loneliness", "Lack of Support", and "Dependence") contributes to the likelihood of adapting a "Resigning to Life \& Reducing Activity" strategy. 
Coping strategies were demonstrated to be fluid and changeable, consistent with previous models [24]. This is shown through the double headed arrow between “Accepting Life \& Adapting Activity" and "Resigning to Life \& Reducing Activity". A person with SPMS may therefore change their mode of coping in conjunction with changes in their support network, independence, and professional emotional and informational support. In this line of argument, "accepting" and "adapting" strategies are grouped together, as we found that to adapt activity, participants also needed to accept life, and that "adapting" and "accepting" do not occur in isolation of one another.

We found that style of coping is situational, and similar to the dual process "pendulum" model described in grief coping research [39]. In this model, oscillation occurs between two orientations of coping ("accepting" and "adapting" versus "resigning" and "reducing"), which is partly conditional (e.g., on availability of supports). In some situations, a person with SPMS may accept and adapt to their condition (e.g., making environmental adjustments to continue seeing their family), but in other situations they may resign and reduce (e.g., stopping household chores). Over time, several factors (e.g., changing relationships) will impact on the dominant modes of coping in response to each situation.

Gradually, as persons with SPMS become more restricted by their condition, they will likely need additional support from others. This line of argument highlights that - if this increasing need for others is experienced as a loss of independence (i.e., a felt sense of "dependence”) - persons with SPMS will likely orient to increased "Resigning to Life \& Reducing Activity" coping, leading to a reduced quality of life.

\section{Discussion}

This synthesis of 12 papers highlights that successful adjustment to SPMS 
depends primarily on the coping strategies that a patient uses, and that the chosen strategy is influenced by the individual's felt sense of independence, the professional support they receive and their social support network.

Previous adjustment literature has distinguished between engagement coping (approaching and dealing with challenges and related emotions - e.g., through problemsolving, support-seeking, and active acceptance) versus disengagement coping (avoiding and escaping from challenges and related emotions - e.g., through denial, avoidance, and passive resignation) - and found that disengagement coping is generally maladaptive [40]. The line of argument in this study follows a similar trajectory, with the "disengagement" strategies mapping on to the "Resigning to Life \& Reducing Activity" and "engagement" strategies on to "Accepting Life \& Adapting Activity". The crucial importance of a disengaged/avoidant coping style predicting worse adjustment was the strongest and most consistent finding of a separate previous systematic review into coping with adjustment in MS [41], and we therefore suggest that the adjustment of people to SPMS relies on similar mechanisms to those with other subtypes.

Dennison et al. [41] also identified uncertainty (i.e., poor knowledge of MS and helplessness in MS) as related to worse adjustment - and having a high perceived level of social support as related to better adjustment -both findings which are strongly supported by our review. Interestingly, participants in our review rarely commented on their illness severity or symptoms as having a large impact on their adjustment. When mentioned, it was frequently because they were unable to tend to relationships or partake in previously enjoyable activity. This concurs with the findings of McCabe et al. [42], who observed a minimal relationship between health-related variables and 
adjustment, and highlighted that people with MS remaining involved in their daily activities was of a far greater importance [42].

\section{Implications for practice}

Implications of this research for healthcare services include encouraging clinicians to be forthcoming with informational support and be open with patients throughout the SPMS diagnosis process and during the progression of their condition, as uncertainty was shown to cause patients more distress than realistic understanding of the course of the illness and symptoms. Care should be taken to inform patients about their SPMS diagnosis sensitively. Professional support (including psychological support), which more closely matches that provided for an initial MS diagnosis, should be afforded to help patients with queries and concerns. This may help prevent those with SPMS who currently feel "abandoned" [12,p.8] after SPMS diagnosis by services.

Short-term emotional support would be apt to support adjustment, and this should focus on the primary determinants of successful adjustment in SPMS, which are the development of disengagement (versus engagement) coping strategies. Foci of support may thus include reducing avoidance, increasing physical activity, and assisting in the maintenance or improvement of a patient's social network. A "third wave behaviour therapy", such as Acceptance and Commitment Therapy [43], may be appropriate for developing these strategies, because traditional Cognitive Behavioural Therapy techniques [44] (such as challenging beliefs around illness) may be inappropriate when the beliefs are indeed accurate.

\section{Strengths and Limitations}

The systematic identification of papers and their critical appraisal by at least two reviewers arguably enhanced the rigour of the synthesis. Some of the papers included in 
this review contained mixed MS subtypes with quotations specific to SPMS participants, but the authors' second-order themes were attributable to the whole sample [e.g. 45]. However, the themes generated in this review being consistent with those of the "key papers" (See table 4) increases confidence that the review reflects the views and opinions specifically of those with SPMS.

One limitation of this synthesis is that we only included published papers, excluding "grey literature", which means that some useful literature may have been missed. Some papers did not specify whether a participant had SPMS, or a different subtype, and therefore potentially valuable papers needed to be excluded from the synthesis to ensure only those diagnosed and adjusting to SPMS were represented to avoid convoluting the data [e.g., 19,46]. With included papers, it was occasionally difficult to ensure that quotations were attributable to those with SPMS, and many therefore had to be omitted [e.g., 47]. Synthesising is inherently interpretative and is prone to bias or preferred perspective-taking with only few interpreters. Such bias was mitigated by having four researchers with varied preferred psychological models of working, who discussed and debated each other's interpretations to arrive at a consensus.

\section{Conclusion}

People adjust to SPMS in different ways, with the success of adjustment influenced by a patient's primary coping mechanism. The coping mechanism is determined by pre-existing individual differences, along with their engagement with, and quality of, social support networks and activities. Services should ensure that people are provided with informational support about their illness progression, and emotional support concerning coping strategies, social networks and physical activity, as these are key determinants of successful adjustment. 


\section{Declaration of Interest Statement}

The authors report no conflicts of interest.

\section{Acknowledgements}

This work was supported by the Trent Clinical Psychology Doctoral Programme and Health Education England East Midlands.

Word Count: 7471 (Excluding Title Page)

\section{References}

1. Mackenzie IS, Morant SV, Bloomfield GA, et al. Incidence and prevalence of multiple sclerosis in the UK 1990-2010: a descriptive study in the General Practice Research Database. J Neurol Neurosurg Psychiatry. 2014;85(1):76-84.

2. Lublin FD, Reingold SC, Cohen JA, et al. Defining the clinical course of multiple sclerosis: the 2013 revisions. Neurology. 2014 Jul 15;83(3):278-86. eng.

3. Koch M, Kingwell E, Rieckmann P, et al. The natural history of secondary progressive multiple sclerosis. J Neurol Neurosurg Psychiatry. 2010;81(9):10391043.

4. Scalfari A, Neuhaus A, Daumer M, et al. Onset of secondary progressive phase and long-term evolution of multiple sclerosis. J Neurol Neurosurg Psychiatry. 2014;85(1):67-75.

5. Katz Sand I, Krieger S, Farrell C, et al. Diagnostic uncertainty during the transition to secondary progressive multiple sclerosis. Mult Scler J. 2014;20(12):1654-1657.

6. Wilkinson HR, das Nair R. The psychological impact of the unpredictability of multiple sclerosis: a qualitative literature meta-synthesis. Br J Neurosci Nurs. 2013;9(4):172-178.

7. Edwards RG, Barlow JH, Turner AP. Experiences of diagnosis and treatment among people with multiple sclerosis. J Eval Clin Pract. 2008;14(3):460-464.

8. Giordano A, Granella F, Lugaresi A, et al. Anxiety and depression in multiple sclerosis patients around diagnosis. Journal of the Neurological Sciences. 2011;307(1):86-91.

9. Deibel F, Edwards M, Edwards A. Patients', carers' and providers' experiences and requirements for support in self-management of multiple sclerosis: a qualitative study. Eur J for Pers Cent Healthc. 2013;1(2):457-467.

10. Fogarty E, Schmitz S, Tubridy N, et al. Comparative efficacy of diseasemodifying therapies for patients with relapsing remitting multiple sclerosis: Systematic review and network meta-analysis. Multiple Sclerosis and Related Disorders. 2016;9:23-30. 
11. Coetzee T, Zaratin P, Gleason TL. Overcoming barriers in progressive multiple sclerosis research. The Lancet Neurology. 2015;14(2):132-133.

12. Davies F, Edwards A, Brain K, et al. You are just left to get on with it: Qualitative study of patient and carer experiences of the transition to secondary progressive multiple sclerosis. BMJ Open. 2015;5 (7):1-10.

13. Thorne S, Con A, McGuinness L, et al. Health Care Communication Issues in Multiple Sclerosis: An Interpretive Description. Qualitative Health Research. 2004;14(1):5-22.

14. Fox RJ, Thompson A, Baker D, et al. Setting a research agenda for progressive multiple sclerosis: The International Collaborative on Progressive MS. Multiple Sclerosis Journal. 2012;18(11):1534-1540.

15. Lorefice L, Mura G, Coni G, et al. What do multiple sclerosis patients and their caregivers perceive as unmet needs? BMC Neurology. 2013;13(1):177.

16. Koffman J, Gao W, Goddard C, et al. Progression, Symptoms and Psychosocial Concerns among Those Severely Affected by Multiple Sclerosis: A MixedMethods Cross-Sectional Study of Black Caribbean and White British People. PLoS ONE. 2013;8 (10):1-11.

17. Boeije HR, Duijnstee MS, Grypdonck MH, et al. Encountering the downward phase: biographical work in people with multiple sclerosis living at home. Social Science \& Medicine. 2002;55(6):881-93.

18. Chen H, Habermann B. Ready or not: Planning for health declines in couples with advanced multiple sclerosis. Journal of Neuroscience Nursing. 2013;45(1):38-43.

19. Edmonds P, Vivat B, Burman R, et al. 'Fighting for everything': service experiences of people severely affected by multiple sclerosis. Multiple Sclerosis. 2007;13(5):660-667.

20. Jones KH, Ford DV, Jones PA, et al. A Large-Scale Study of Anxiety and Depression in People with Multiple Sclerosis: A Survey via the Web Portal of the UK MS Register. PLOS ONE. 2012;7(7).

21. Carta MG, Moro MF, Lorefice L, et al. Multiple sclerosis and bipolar disorders: The burden of comorbidity and its consequences on quality of life. Journal of Affective Disorders. 2014;167:192-197.

22. Kobelt G, Berg J, Lindgren P, et al. Costs and quality of life of patients with multiple sclerosis in Europe. Journal of Neurology, Neurosurgery \& Psychiatry. 2006;77(8):918-926.

23. O'Loughlin E, Hourihan S, Chataway J, et al. The experience of transitioning from relapsing remitting to secondary progressive multiple sclerosis: views of patients and health professionals. Disability \& Rehabilitation. 2017;39(18):1821-1828.

24. Bogosian A, Morgan M, Bishop FL, et al. Adjustment modes in the trajectory of progressive multiple sclerosis: a qualitative study and conceptual model. Psychology \& health. 2017;32(3):343-360.

25. Moss-Morris R. Adjusting to chronic illness: Time for a unified theory. British Journal of Health Psychology. 2013;18(4):681-686.

26. Lachal J, Revah-Levy A, Orri M, et al. Metasynthesis: An Original Method to Synthesize Qualitative Literature in Psychiatry. Frontiers in psychiatry. 2017;8:269-269.

27. Tong A, Flemming K, McInnes E, et al. Enhancing transparency in reporting the synthesis of qualitative research: ENTREQ. BMC Medical Research Methodology. 2012;12(1):181. 
28. Malpass A, Shaw A, Sharp D, et al. "Medication career" or "Moral career"? The two sides of managing antidepressants: A meta-ethnography of patients' experience of antidepressants. Social Science \& Medicine. 2009;68(1):154-168.

29. Noblit GW, Hare RD, Hare R. Meta-ethnography: Synthesizing qualitative studies. Newbury Park, CA: Sage; 1988.

30. Shaw RL. Conducting literature reviews. In: Forrester MA (Ed.), Doing Qualitative Research in Psychology: A Practical Guide. London: Sage; 2010. p. 39-56.

31. Bramer W, Bain P. Updating search strategies for systematic reviews using EndNote. J Med Libr Assoc. 2017;105(3):285-289.

32. Critical Appraisal Skills Programme [Internet] Oxford: CASP; [cited 2018 Oct 26]. Available from: https://casp-uk.net/wp-content/uploads/2018/03/CASPQualitative-Checklist-2018 fillable form.pdf

33. Dixon-Woods M, Shaw RL, Agarwal S, et al. The problem of appraising qualitative research. Quality and Safety in Health Care. 2004;13(3):223.

34. Dixon-Woods M, Sutton A, Shaw R, et al. Appraising qualitative research for inclusion in systematic reviews: a quantitative and qualitative comparison of three methods. J Health Serv Res Policy. 2007;12(1):42-47.

35. Britten N, Campbell R, Pope C, et al. Using meta ethnography to synthesise qualitative research: a worked example. J Health Serv Res Policy. 2002;7(4):209-15.

36. Thorne S, Jensen L, Kearney MH, et al. Qualitative Metasynthesis: Reflections on Methodological Orientation and Ideological Agenda. Qualitative Health Research. 2004;14(10):1342-1365.

37. Orton S-M, Herrera BM, Yee IM, et al. Sex ratio of multiple sclerosis in Canada: a longitudinal study. The Lancet Neurology. 2006;5(11):932-936.

38. Matud MP. Gender differences in stress and coping styles. Personality and Individual Differences. 2004;37(7):1401-1415.

39. Stroebe M, Schut H. The dual process model of coping with bereavement: rationale and description. Death studies. 1999;23(3):197-224.

40. Hofmann SG, Hay AC. Rethinking avoidance: Toward a balanced approach to avoidance in treating anxiety disorders. Journal of Anxiety Disorders. 2018;55:14-21.

41. Dennison L, Moss-Morris R, Chalder T. A review of psychological correlates of adjustment in patients with multiple sclerosis. Clinical psychology review. 2009;29(2):141-53.

42. McCabe MP, McKern S, McDonald E. Coping and psychological adjustment among people with multiple sclerosis. Journal of psychosomatic research. 2004;56(3):355-61.

43. Hayes SC. Acceptance and commitment therapy, relational frame theory, and the third wave of behavioral and cognitive therapies. Behavior Therapy. 2004;35(4):639-665.

44. Beck A, Rush A, Shaw B, et al. Cognitive treatment of depression: A treatment manual. New York: Guilford; 1979.

45. Giovannetti AM, Brambilla L, Torri Clerici V, et al. Difficulties in adjustment to multiple sclerosis: vulnerability and unpredictability of illness in the foreground. Disability and rehabilitation. 2017;39(9):897-903.

46. Kirkpatrick Pinson DM, Ottens AJ, Fisher TA. Women coping successfully with multiple sclerosis and the precursors of change. Qualitative Health Research. 2009;19(2):181-193. 
47. Lexell EM, Lund ML, Iwarsson S. Constantly changing lives: experiences of people with multiple sclerosis. Am J Occup Ther. 2009;63(6):772-781.

48. Bogosian A, Morgan M, Moss-Morris R. Multiple challenges for people after transitioning to secondary progressive multiple sclerosis: a qualitative study. BMJ Open. 2019;9(3):e026421.

49. Borreani C, Bianchi E, Pietrolongo E, et al. Unmet needs of people with severe multiple sclerosis and their carers: Qualitative findings for a home-based intervention. PLoS ONE. 2014;9 (10).

50. Dennison L, Yardley L, Devereux A, et al. Experiences of adjusting to early stage Multiple Sclerosis. Journal of health psychology. 2011;16(3):478-488.

51. Frost J, Grose J, Britten N. A qualitative investigation of lay perspectives of diagnosis and self-management strategies employed by people with progressive multiple sclerosis. Health. 2017;21(3):316-336.

52. Koffman J, Goddard C, Gao W, et al. Exploring meanings of illness causation among those severely affected by multiple sclerosis: A comparative qualitative study of Black Caribbean and White British people. BMC Palliat Care. 2015;14(1):13.

53. Olsson M, Lexell J, Söderberg S. The Meaning of Women's Experiences of Living With Multiple Sclerosis. Health Care for Women International. 2008;29(4):416-430. 
Appendix 1. Embase search strategy.

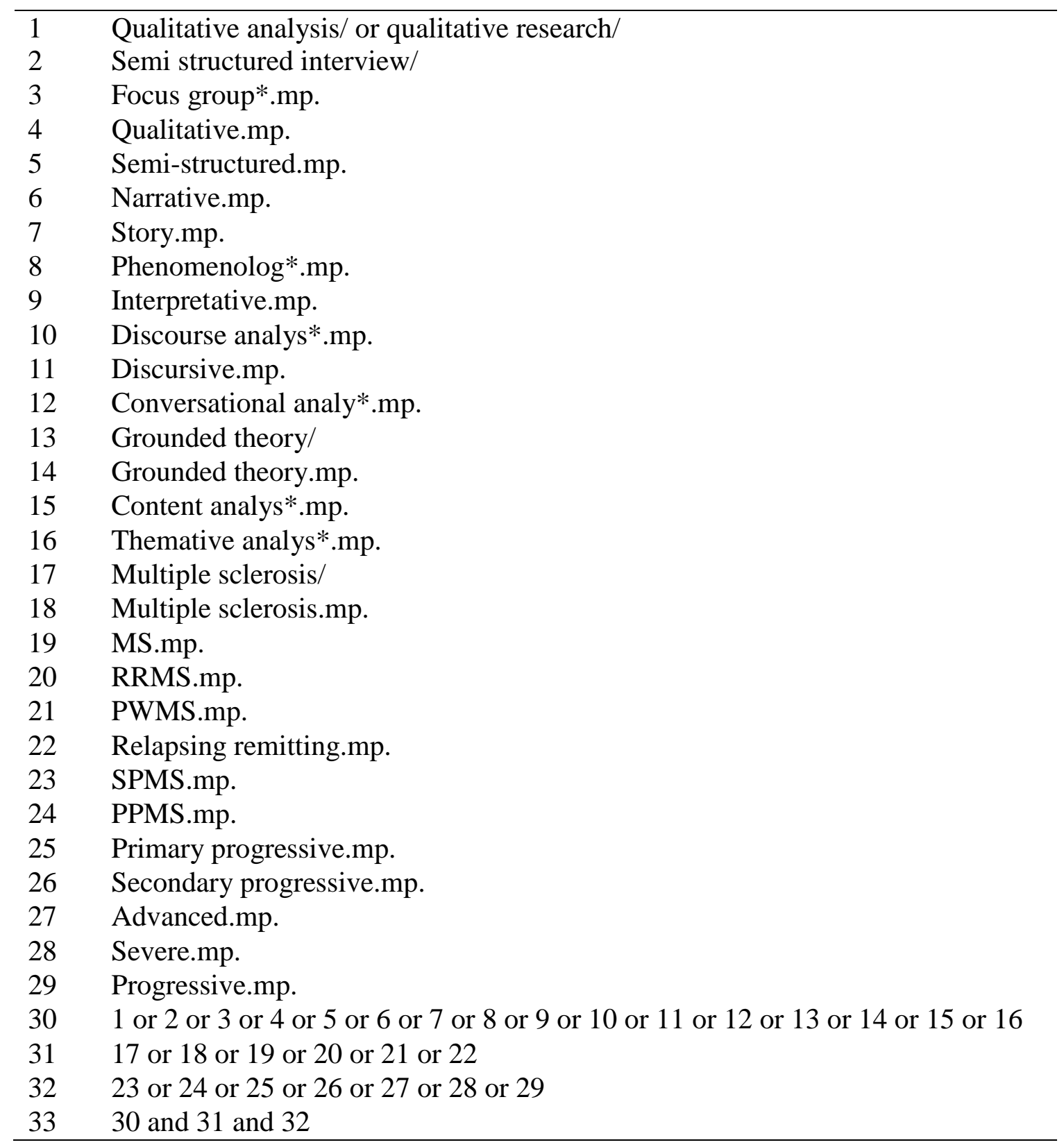


Table 1. The component parts of the search strategy using the CHIP tool

\begin{tabular}{ll}
\hline Component & Formulation \\
\hline Context & $\begin{array}{l}\text { Secondary Progressive Multiple Sclerosis } \\
\text { Qualitative research }\end{array}$ \\
Issues of interest & $\begin{array}{l}\text { The psychosocial adjustment to SPMS and the needs of } \\
\text { this group (during, or after diagnosis) }\end{array}$ \\
Population & $\begin{array}{l}\text { Adults with SPMS reflecting on their current or previous } \\
\text { adjustment to the condition }\end{array}$ \\
\hline
\end{tabular}


Table 2. Summary of characteristics of included studies.

\begin{tabular}{|c|c|c|c|c|c|c|c|c|}
\hline $\begin{array}{l}\text { Paper } \\
\#\end{array}$ & $\begin{array}{l}\text { Authors } \\
\text { (Year) }\end{array}$ & Country & Sample size & $\begin{array}{l}\text { Mean } \\
\text { age } \\
\text { (range) }\end{array}$ & Gender & $\begin{array}{l}\text { Methods } \\
\text { of data } \\
\text { collection }\end{array}$ & Data analysis & Aim \\
\hline 1 & $\begin{array}{l}\text { Bogosian, } \\
\text { Morgan } \\
{[24]}\end{array}$ & UK & $\begin{array}{l}34 \text { pwMS }(13 \\
\text { PPMS, } 21 \\
\text { SPMS })\end{array}$ & $\begin{array}{l}55 \\
(39-77)\end{array}$ & $\begin{array}{l}73.5 \% \\
\text { women, } \\
26.5 \% \text { men }\end{array}$ & $\begin{array}{l}\text { Semi } \\
\text { structured } \\
\text { interviews } \\
\text { (phone) }\end{array}$ & Grounded Theory & $\begin{array}{l}\text { Examine cognitive and behavioural } \\
\text { challenges and adaptations for people } \\
\text { with progressive MS and develop a } \\
\text { conceptual model of change in } \\
\text { adjustment over time }\end{array}$ \\
\hline 2 & $\begin{array}{l}\text { Bogosian, } \\
\text { Morgan } \\
{[48]}\end{array}$ & UK & 21 SPMS & $\begin{array}{l}57.3 \\
(40-77)\end{array}$ & $\begin{array}{l}72.7 \% \\
\text { women, } \\
27.3 \% \text { men }\end{array}$ & $\begin{array}{l}\text { Semi } \\
\text { structured } \\
\text { interviews } \\
\text { with } \\
\text { follow up }\end{array}$ & $\begin{array}{l}\text { Inductive thematic } \\
\text { analysis }\end{array}$ & $\begin{array}{l}\text { Examine the challenges people face } \\
\text { when diagnosed with SPMS by } \\
\text { exploring experiences of those who } \\
\text { have transitioned recently }\end{array}$ \\
\hline 3 & $\begin{array}{l}\text { Borreani, } \\
\text { Bianchi [49] }\end{array}$ & Italy & $\begin{array}{l}22 \text { pwMS }(6 \\
\text { PPMS, } 16 \\
\text { SPMS })\end{array}$ & $\begin{array}{l}58.7 \\
(41-77)\end{array}$ & $\begin{array}{l}64 \% \\
\text { women, } \\
36 \% \text { men }\end{array}$ & $\begin{array}{l}\text { Semi } \\
\text { structured } \\
\text { interviews }\end{array}$ & Grounded Theory & $\begin{array}{l}\text { Identify unmet needs of people with } \\
\text { severe MS and their carers to inform } \\
\text { development of a home-based } \\
\text { intervention }\end{array}$ \\
\hline 4 & $\begin{array}{l}\text { Davies, } \\
\text { Edwards } \\
{[12]}\end{array}$ & UK & $\begin{array}{l}20 \text { SPMS, } 13 \\
\text { Carers }\end{array}$ & NR & $\begin{array}{l}75 \% \\
\text { women, } \\
25 \% \text { men }\end{array}$ & $\begin{array}{l}\text { Semi } \\
\text { structured } \\
\text { interviews }\end{array}$ & $\begin{array}{l}\text { Inductive thematic } \\
\text { analysis }\end{array}$ & $\begin{array}{l}\text { Explore the experiences of pwMS } \\
\text { transitioning from RRMS to SPMS } \\
\text { and identify support needs }\end{array}$ \\
\hline
\end{tabular}




\begin{tabular}{|c|c|c|c|c|c|c|c|c|}
\hline 5 & $\begin{array}{l}\text { Deibel, } \\
\text { Edwards [9] }\end{array}$ & UK & $\begin{array}{l}29 \text { pwMS + } \\
\text { carers }(12 \\
\text { SPMS })\end{array}$ & 51 (NR) & $\begin{array}{l}54 \% \\
\text { women, } \\
46 \% \text { men }\end{array}$ & $\begin{array}{l}\text { Focus } \\
\text { group }\end{array}$ & $\begin{array}{l}\text { Inductive thematic } \\
\text { analysis }\end{array}$ & $\begin{array}{l}\text { Identify requirements and provide } \\
\text { recommendations for self- } \\
\text { management support. }\end{array}$ \\
\hline 6 & $\begin{array}{l}\text { Dennison, } \\
\text { Yardley } \\
{[50]}\end{array}$ & UK & $\begin{array}{l}30 \text { pwMS }(8 \\
\text { SPMS) }\end{array}$ & NR & $\begin{array}{l}73 \% \\
\text { women, } \\
27 \% \text { men }\end{array}$ & $\begin{array}{l}\text { Telephone } \\
\text { interviews }\end{array}$ & $\begin{array}{l}\text { Inductive thematic } \\
\text { analysis }\end{array}$ & $\begin{array}{l}\text { Explore psychosocial adjustment to } \\
\text { living with early stage MS }\end{array}$ \\
\hline 7 & $\begin{array}{l}\text { Frost, Grose } \\
{[51]}\end{array}$ & UK & $\begin{array}{l}14 \text { pwMS }(5 \\
\text { SPMS })\end{array}$ & $\begin{array}{l}59 \\
(40-73)\end{array}$ & $\begin{array}{l}71.5 \% \\
\text { women, } \\
28.5 \% \text { men }\end{array}$ & $\begin{array}{l}\text { Interviews } \\
\text { with } \\
\text { follow up } \\
\text { (6 mth) }\end{array}$ & $\begin{array}{l}\text { Iterative reading and } \\
\text { recording of themes }\end{array}$ & $\begin{array}{l}\text { Explore how people with progressive } \\
\text { MS make sense of their experiences }\end{array}$ \\
\hline 8 & $\begin{array}{l}\text { Giovannetti, } \\
\text { Brambilla } \\
\text { [45] }\end{array}$ & Italy & $\begin{array}{l}19 \text { pwMS (1 } \\
\text { SPMS) }\end{array}$ & $\begin{array}{l}36.6 \\
(19-57)\end{array}$ & $\begin{array}{l}68 \% \\
\text { women, } \\
32 \% \text { men }\end{array}$ & $\begin{array}{l}\text { Semi } \\
\text { structured } \\
\text { interviews }\end{array}$ & $\begin{array}{l}\text { Inductive thematic } \\
\text { analysis }\end{array}$ & $\begin{array}{l}\text { Explore the illness experiences of } \\
\text { people with difficulties in adjustment } \\
\text { to MS }\end{array}$ \\
\hline 9 & $\begin{array}{l}\text { Koffman, } \\
\text { Goddard } \\
{[52]}\end{array}$ & UK & $\begin{array}{l}30 \text { pwMS (13 } \\
\text { SPMS) }\end{array}$ & NR & $\begin{array}{l}66.6 \% \\
\text { women, } \\
33.3 \% \text { men }\end{array}$ & $\begin{array}{l}\text { Face-to- } \\
\text { face } \\
\text { interviews }\end{array}$ & $\begin{array}{l}\text { Coding themes and } \\
\text { achieving consensus } \\
\text { through discussion }\end{array}$ & $\begin{array}{l}\text { Explore the presence and construction } \\
\text { of meanings among Black Caribbean } \\
\text { and White British pwMS }\end{array}$ \\
\hline 10 & $\begin{array}{l}\text { Lexell, Lund } \\
{[47]}\end{array}$ & Sweden & $\begin{array}{l}10 \text { pwMS }(8 \\
\text { SPMS) }\end{array}$ & $\begin{array}{l}53.4 \\
(41-67)\end{array}$ & $\begin{array}{l}60 \% \\
\text { women, } \\
40 \% \text { men }\end{array}$ & $\begin{array}{l}\text { Semi } \\
\text { structured } \\
\text { interviews }\end{array}$ & $\begin{array}{l}\text { Grounded Theory, } \\
\text { Constant } \\
\text { Comparative }\end{array}$ & $\begin{array}{l}\text { Gain enhanced understanding of how } \\
\text { people with MS experience } \\
\text { engagement in occupations }\end{array}$ \\
\hline 11 & $\begin{array}{l}\text { O'Loughlin, } \\
\text { Hourihan } \\
{[23]}\end{array}$ & UK & 9 SPMS, 7 HCPs & $\begin{array}{l}51 \\
(43-68)\end{array}$ & $\begin{array}{l}77.7 \% \\
\text { women, } \\
23.3 \% \text { men }\end{array}$ & $\begin{array}{l}\text { Semi } \\
\text { structured } \\
\text { interviews }\end{array}$ & $\begin{array}{l}\text { Inductive thematic } \\
\text { analysis }\end{array}$ & $\begin{array}{l}\text { Explore the experiences, coping and } \\
\text { needs associated with the transition } \\
\text { from RRMS to SPMS }\end{array}$ \\
\hline
\end{tabular}




\begin{tabular}{|c|c|c|c|c|c|c|}
\hline 12 & $\begin{array}{l}\text { Olsson, } \\
\text { Lexell [53] }\end{array}$ & Sweden 10 SPMS & $\begin{array}{l}49 \\
(43-59)\end{array}$ & $\begin{array}{l}100 \% \\
\text { women }\end{array}$ & $\begin{array}{l}\text { Face to } \\
\text { face } \\
\text { interviews }\end{array}$ & $\begin{array}{l}\text { Narrative approach, Explore the meaning of women's } \\
\text { Phenomenological experiences of living with MS } \\
\text { Hermeneutic } \\
\text { Interpretation }\end{array}$ \\
\hline
\end{tabular}

Key: NR - Not Reported; MS - Multiple Sclerosis; pwMS - people with MS; RRMS - Relapsing remitting MS; PPMS - Primary progressive MS; SPMS - Secondary progressive MS; HCPs - Healthcare professionals 
Table 3. Quality assessment of papers.

\begin{tabular}{|c|c|c|c|c|c|c|c|c|c|c|c|}
\hline \# & $\begin{array}{l}\text { Key } \\
\text { Paper }\end{array}$ & $\begin{array}{l}\text { Clear } \\
\text { statement } \\
\text { of aims }\end{array}$ & $\begin{array}{l}\text { Appropriate } \\
\text { qualitative } \\
\text { methodology }\end{array}$ & $\begin{array}{l}\text { Appropriate } \\
\text { research } \\
\text { design }\end{array}$ & $\begin{array}{l}\text { Appropriate } \\
\text { recruitment } \\
\text { strategy }\end{array}$ & $\begin{array}{l}\text { Data } \\
\text { collection } \\
\text { sufficiently } \\
\text { addresses } \\
\text { research issue }\end{array}$ & $\begin{array}{l}\text { Relationship } \\
\text { between } \\
\text { researcher } \\
\text { and } \\
\text { participants } \\
\text { considered }\end{array}$ & $\begin{array}{l}\text { Ethical issues } \\
\text { considered }\end{array}$ & $\begin{array}{l}\text { Data analysis } \\
\text { sufficiently } \\
\text { rigorous }\end{array}$ & $\begin{array}{l}\text { Clear } \\
\text { statement } \\
\text { of findings }\end{array}$ & $\begin{array}{l}\text { How } \\
\text { valuable }\end{array}$ \\
\hline 1 & KP & Yes (S) & Yes (S) & Yes (S) & Yes (S) & Yes (S) & Unclear (NR) & Yes (S) & Yes $(\mathrm{S})$ & Yes (S) & Valuable \\
\hline 2 & $\mathrm{KP}$ & Yes $(S)$ & Yes (S) & Yes (S) & Yes $(S)$ & Yes $(\mathrm{S})$ & Yes $(S)$ & Yes $(S)$ & Yes $(S)$ & Yes $(S)$ & Valuable \\
\hline 3 & SAT & Yes (S) & Yes (S) & Yes (S) & Yes (S) & Yes (P) & Unclear (NR) & Yes (S) & Yes $(\mathrm{P})$ & Yes (S) & Valuable \\
\hline 4 & $\mathrm{KP}$ & Yes (S) & Yes (S) & Yes (S) & Yes (S) & Yes (S) & Unclear (NR) & Yes (S) & Yes $(\mathrm{P})$ & Yes (S) & Valuable \\
\hline 5 & SAT & Yes (S) & Yes (S) & Yes (S) & Yes (S) & Yes (S) & Unclear (NR) & Yes (S) & Yes $(S)$ & Yes (S) & Valuable \\
\hline 6 & SAT & Yes (S) & Yes (S) & Yes (S) & Yes (S) & Yes (S) & Yes $(\mathrm{P})$ & Yes $(S)$ & Yes $(\mathrm{S})$ & Yes (P) & Valuable \\
\hline 7 & SAT & Yes (S) & Yes (S) & Yes (S) & Yes (S) & Yes (S) & Unclear (NR) & Unclear (NR) & Yes $(\mathrm{S})$ & Yes (P) & Valuable \\
\hline 8 & SAT & Yes $(S)$ & Yes (S) & Yes (S) & Yes (P) & Yes (S) & Unclear (NR) & Yes $(\mathrm{S})$ & Yes $(\mathrm{S})$ & Yes (P) & Valuable \\
\hline 9 & SAT & Yes (S) & Yes (S) & Yes (S) & Yes (S) & Yes (S) & Yes $(S)$ & Yes (S) & Unclear (NR) & Yes $(\mathrm{P})$ & Valuable \\
\hline 10 & SAT & Yes $(S)$ & Yes (S) & $\begin{array}{l}\text { Unclear } \\
\text { (NS) }\end{array}$ & Yes (P) & Yes $(\mathrm{P})$ & Unclear (NR) & Yes $(\mathrm{P})$ & Yes $(S)$ & Yes (S) & Valuable \\
\hline 11 & $\mathrm{KP}$ & Yes (S) & Yes (S) & Yes (S) & Yes (S) & Yes (S) & Unclear (NR) & Yes $(\mathrm{P})$ & Yes $(\mathrm{S})$ & Yes (S) & Valuable \\
\hline 12 & SAT & Yes (P) & Yes (S) & Yes (S) & Yes (P) & Yes (P) & Unclear (NR) & Yes (P) & Yes (P) & $\begin{array}{l}\text { Unclear } \\
\text { (NS) }\end{array}$ & Valuable \\
\hline
\end{tabular}

Key: S - Fully or mostly satisfied; P - Partially satisfied; NR - Not reported; NS - Not satisfied; KP - Key Paper; SAT - Satisfactory Paper 
Table 4. Themes and subthemes derived from the studies reviewed.

\begin{tabular}{|c|c|c|c|}
\hline Theme & Sub-theme & Number of studies & Study reference numbers \\
\hline \multirow[t]{3}{*}{ Coping Strategies } & Denying and Concealing & 7 & $1,2,4,6,7,11,12$ \\
\hline & Reducing and Resigning & 6 & $\mathbf{1 , 2 , 4 , 7 , 1 0 , 1 1}$ \\
\hline & Accepting and Adapting & 7 & $1,2,3,4,7,11,12$ \\
\hline \multirow[t]{2}{*}{ Symptoms } & Physical & 7 & $1,2,3,4,5,11,12$ \\
\hline & Cognitive & 1 & 1 \\
\hline \multirow[t]{2}{*}{ Impact on Relationships } & Social Connectiveness & 10 & $\mathbf{1 , 2}, 3, \mathbf{4}, 5,6,7,8, \mathbf{1 1}, 12$ \\
\hline & Sexuality & 1 & 3 \\
\hline \multirow[t]{3}{*}{ Loss } & Independence & 5 & $\mathbf{1 , 3 , 4 , 7 , 1 0}$ \\
\hline & Role & 5 & $4,5,8,10,12$ \\
\hline & Confidence & 4 & $1,2,7,12$ \\
\hline \multirow[t]{2}{*}{ The time of the SPMS diagnosis } & Delivering the SPMS diagnosis & 5 & $\mathbf{2 , 4 , 7 , 1 1 , 1 2}$ \\
\hline & Reaction to the SPMS diagnosis & 4 & $2,4,10,11$ \\
\hline
\end{tabular}

Note. Bold font represents a Key Paper 
Figure 1. PRISMA diagram showing the article screening process.

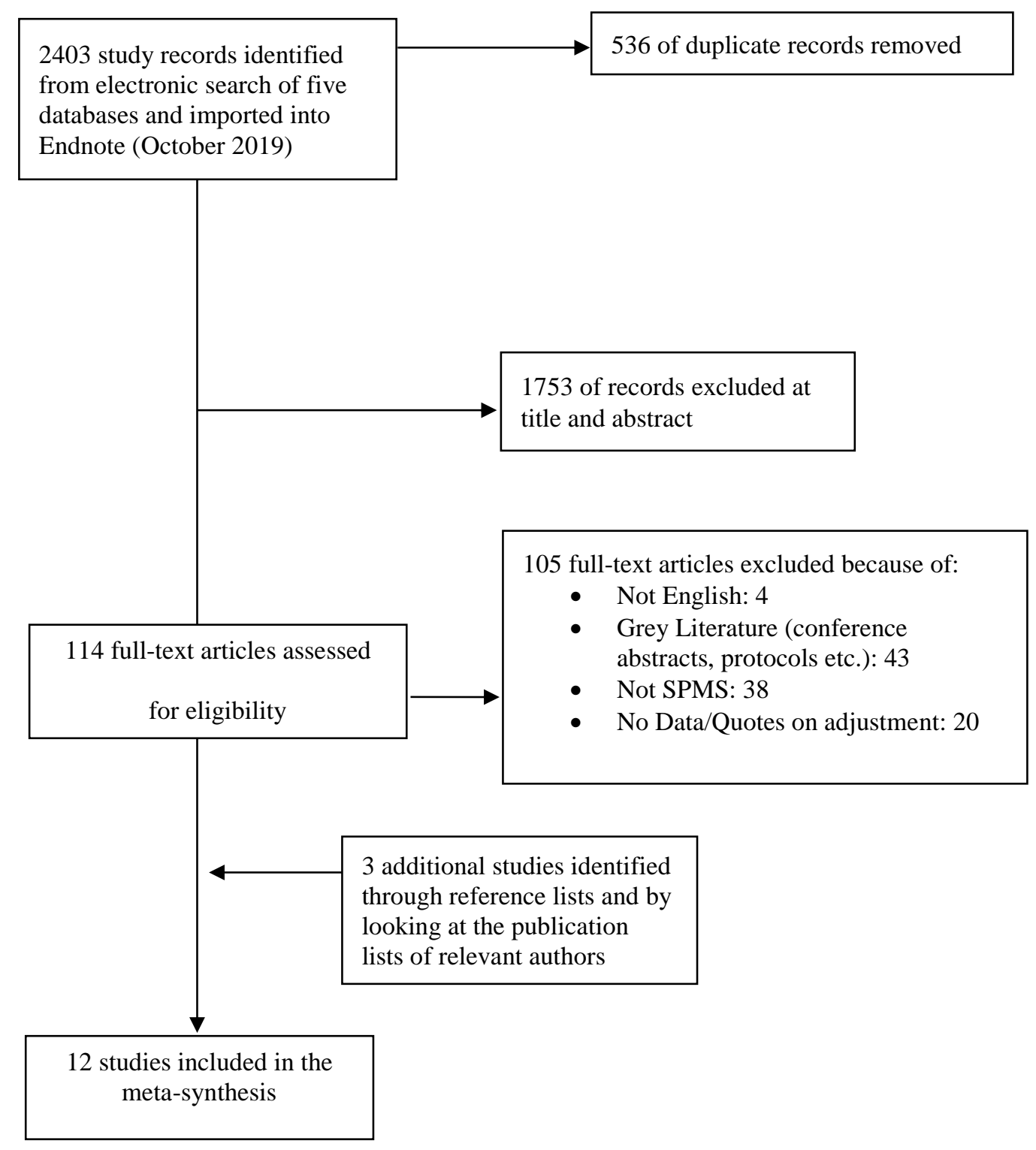


Figure 2. Line of argument showing coping strategies utilised by those with SPMS.

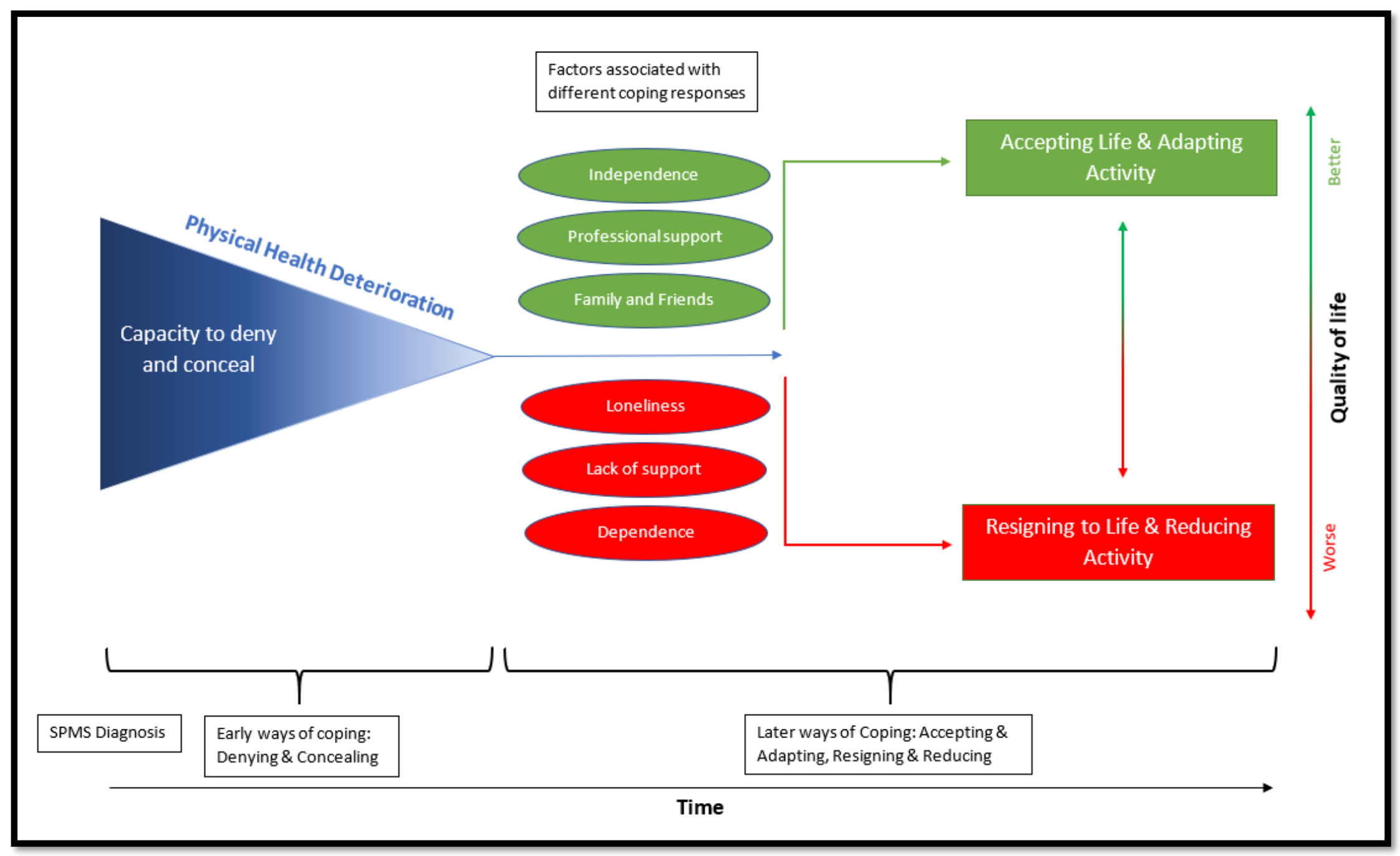

